\title{
THE TEXTURE DEVELOPMENT OF Ti-Ni-Cu WIRE DURING THERMOMECHANICAL CYCLING
}

\author{
P.F. WILLEMSE, B.J. KOOPMAN and J. BEYER \\ University of Twente, Faculty of Mechanical Engineering, Laboratory for Materials Science, PO. Box \\ 217, NL-7500 AE Enschede, The Netherlands
}

\begin{abstract}
An investigation has been carried out on the texture of Ti-44Ni-5Cu (at \%) shape memory alloy wire. The texture of the B2 and monoclinic phases has been determined as a function of the degree of cold deformation during the drawing process and the number of cycles on thermomechanical cycling. After cold drawing and annealing (823 $\mathrm{K}, 180 \mathrm{~s})$ under tensile stress, the [110], [110] [101] and [i01] directions in the monoclinic phase are parallel to the wire axis. In this condition a preference for the [101] component is observed. On heating the wire above $A_{f}$ and cooling down, this preference disappears. Subsequently the preference develops again on thermomechanical cycling. The B2 phase shows in all conditions a $\langle 111\rangle$ fiber texture. The observed preference of the [101] fiber texture component in the monoclinic phase is discussed in terms of strain accomodation during plastic deformation.
\end{abstract}

\section{1 - INTRODUCTION}

The shape memory effect of $\mathrm{Ti}-\mathrm{Ni}-(\mathrm{Cu})$ alloys is dependent on the crystallographic orientation, and thus on the texture of the material $[1,2,3]$. It is therefore important to know the texture of these alloys, as well as the effects of mechanical and, or, thermal treatments on the texture.

The aim of this investigation was to determine the texture of a cold-drawn Ti-Ni-Cu wire at temperatures below $M_{f}$ and above $A_{f}$, as well as the effect of the degree of cold deformation and thermomechanical cycling on this texture.

\section{2 - EXPERIMENTAL}

A Ti-44Ni-5Cu (at \%) alloy, supplied by Krupp (GST mbH), was used in this investigation. The supplied wire ( $A_{s}$ temperature $333 \mathrm{~K}$, diameter $8 \mathrm{~mm}$ ) was cold drawn to a diameter of $0.15 \mathrm{~mm}$ in different steps with intermediate annealing treatments at $923 \mathrm{~K}$. Two wires with a final cold deformation of $20.9 \%$ and $67.2 \%$ were produced. Then the wires with the two degrees of cold deformation were annealed at $823 \mathrm{~K}$ for $180 \mathrm{~s}$ under a tensile stress of $-200 \mathrm{MPa}$

Thermomechanical cycling was carried out in a horizontal tensile device, in which the load was transferred onto the wire by a coil spring with a low spring constant. The change in length was measured by an LVDT. The maximum load available was $5 \mathrm{~N}$, which corresponded to a stress of $283 \mathrm{MPa}$. The heating cycles were imposed on the wire by means of a function generator switching the current. Thermal cycling was 
accomplished between room temperature and a temperature above $A_{f}$, with a heating time of 0.1-0.5 s and a total cycle time of $10 \mathrm{~s}$.

Fiber textures were determined by means of $x$-ray diffraction patterns, using a transmission pinhole camera with MoKa radiation [4].

\section{3 - RESULTS AND DISCUSSION}

-Effect of degree of cold-drawing deformation and short heating above $A_{f}$.

Figure 1 shows the diffraction patterns of the 20.9 and $67.2 \%$ deformed cold-drawn martensitic wires after annealing at $823 \mathrm{~K}$ for $180 \mathrm{~s}$ under tensile stress. A preferred orientation can be recognized in both wires. The texture in the $67.2 \%$ deformed wire is clearly sharper than in the $20.9 \%$ deformed one. From both patterns, fiber textures with the [110], [1i0], [101] and [101] crystallographic directions parallel to the wire axis can be determined. However, the [101] component is more pronounced than the other ones. The relatively small volume fraction of the [110] and [110] components can be seen from the the small intensity at $\delta=90^{\circ}$ (see also Fig.3) on the 001 diffraction circles. The small intensity at $\delta=90^{\circ}$ and the relatively great intensity at $\delta \sim 25^{\circ}$ on the 10 i diffraction circle indicate that the volume fraction of the [101] component is smaller than that of the [101] component.

Figure 2 shows the diffraction patterns of wires, which were subsequently heated above $A_{f}$ for $2 \mathrm{~s}$ with a current of $0.5 \mathrm{~A}$ and cooled down again. In this case in the $20.9 \%$ cold-deformed wire a texture can hardly be recognized. From the pattern of the $67.2 \%$ cold-deformed wire it has been determined that there are [110], [110], [101] and [101] fiber-texture components with no clear preference for one of them.

-Texture of the B2 phase.

The texture of the B2 phase was determined by heating the wire, placed in the pinhole camera, with a current of $0.4 \mathrm{~A}$ up to $\sim 353 \mathrm{~K}$, above $A_{f}(-340 \mathrm{~K})$ [5]. The diffraction pattern of the $67.2 \%$ cold-deformed wire is shown in Fig. 4 . The texture was estimated as a <111> fiber texture. In the $20.9 \%$ cold-deformed wire a weak $<111\rangle$ fiber texture was observed.

-Effect of thermomechanical cycling.

The effect of thermomechanical cycling is shown in Fig.5. The starting conditions for the 20.9 and $67.2 \%$ deformed wires were as shown in Figs.2(a) and 2(b) respectively. In this condition, as mentioned above, [110], [1i0], [101] and [101] fiber texture components are present in the martensitic phase without a preference for one of these components. On thermomechanical cycling however, the preference for the [ij01] component develops again, as can be observed from Fig.5. It was also found that after a relatively small number of cycles, no preference was present; for the $20.9 \%$ cold-deformed wire the diffraction pattern after 1140 cyclus was similar to that of Fig.2(a).

The observed $\langle 111\rangle$ fiber texture in the $B 2$ phase did not change on thermomechanical cycling.

-The observed preference of the [i01] fiber texture component after plastic deformation and thermomechanical cycling can possibly be explained as follows. The length of the (i01) vector in the martensitic monoclinic unit cell is greater than those of the (110), (110) and (101) vectors. Starting from the geometry of the unit cell given by Otsuka et al. [6]; $a=2.889 \AA, b=4.120 \AA, c=4.622 \AA$ and $\beta=96.8^{\circ}$, the lengths of the vectors are : $|\overline{1} 01|=5.73 \AA,|101|=5.15 \AA,|110|=|1 \overline{1}|=5.03 \AA$. Thus the [101] fiber texture component, i.e. martensite variant, gives the best accomodation to the tensile deformation during wire drawing and thermomechanical cycling. 
(a)

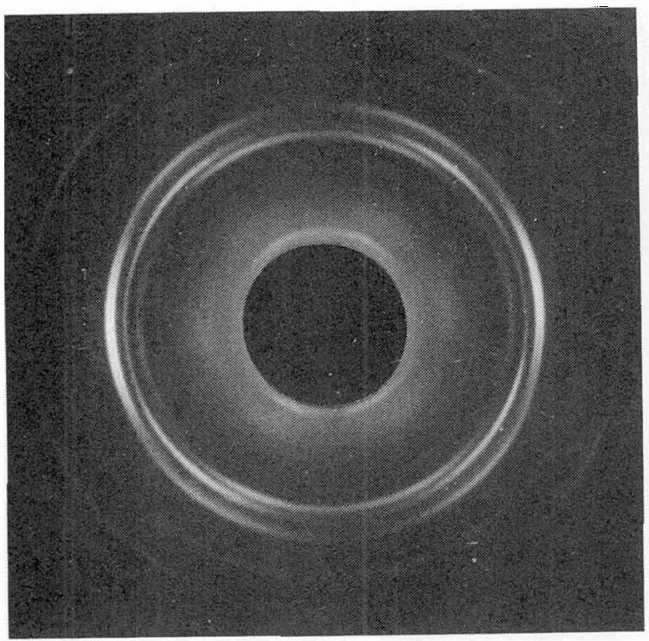

(b)

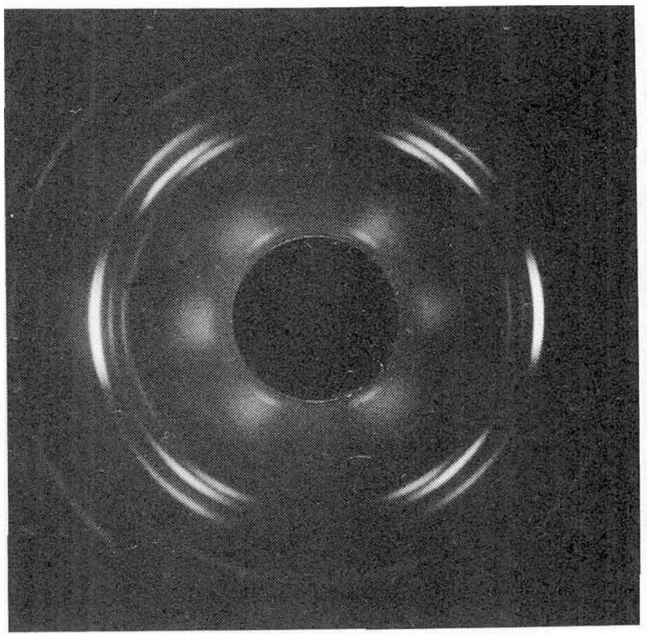

Fig.1 - Diffraction patterns of wires after cold drawing and annealing (823 $\mathrm{K}$, $180 \mathrm{~s}$ ) under tensile stress, (a) $20.9 \%$ cold deformation, (b) $67.2 \%$ cold deformation.

(a)

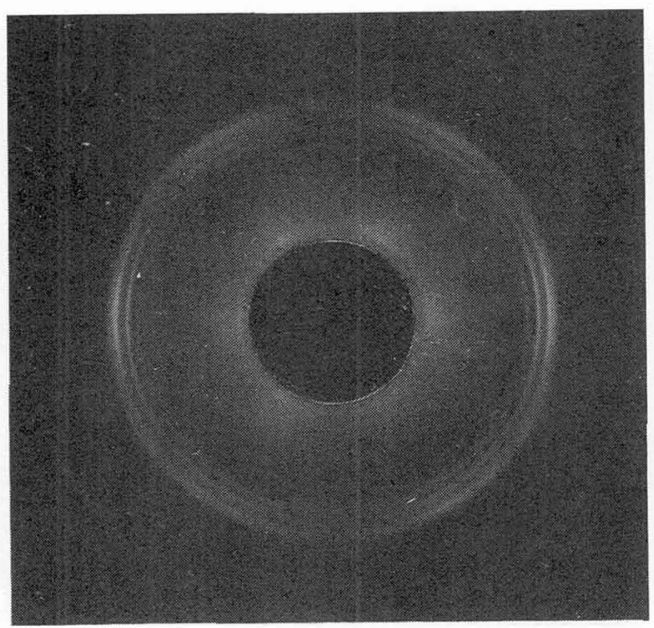

(b)

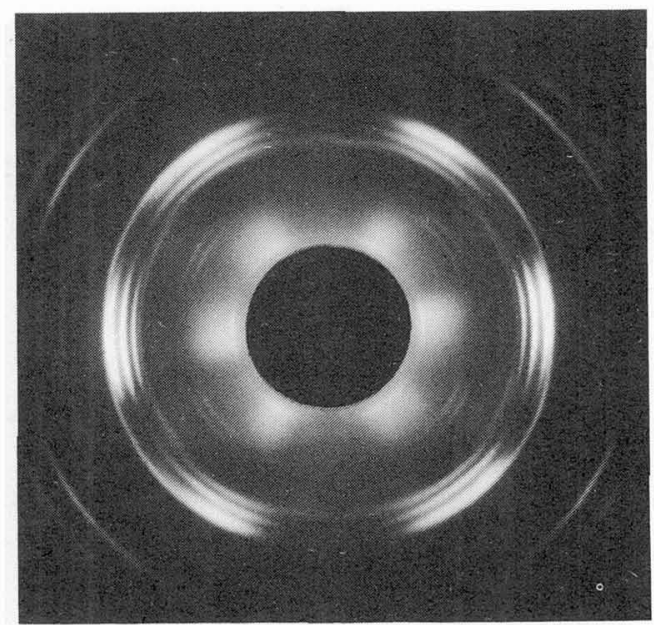

Fig.2 - Diffraction patterns of wires after cold drawing, annealing (823 $\mathrm{K}, 180 \mathrm{~s})$ under tensile stress and heating for $2 \mathrm{~s}$ above $A_{f}$, (a) $20.9 \%$ cold deformation, (b) $67.2 \%$ cold deformation. 


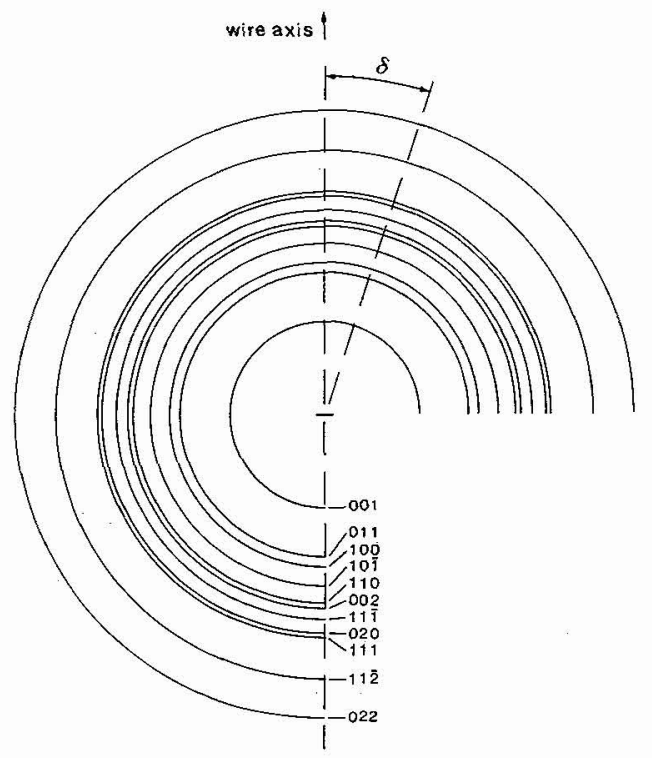

Fig. 3 - Observed reflections with the martensitic phase, and definition of $\delta$.

(a)

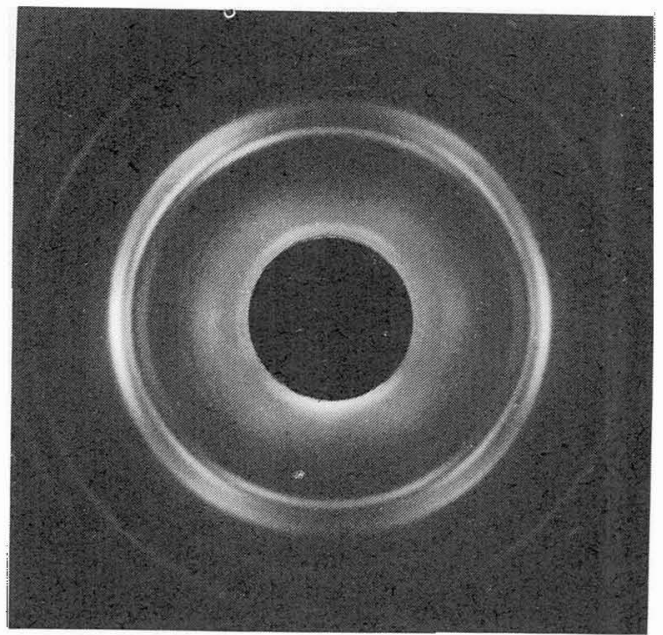

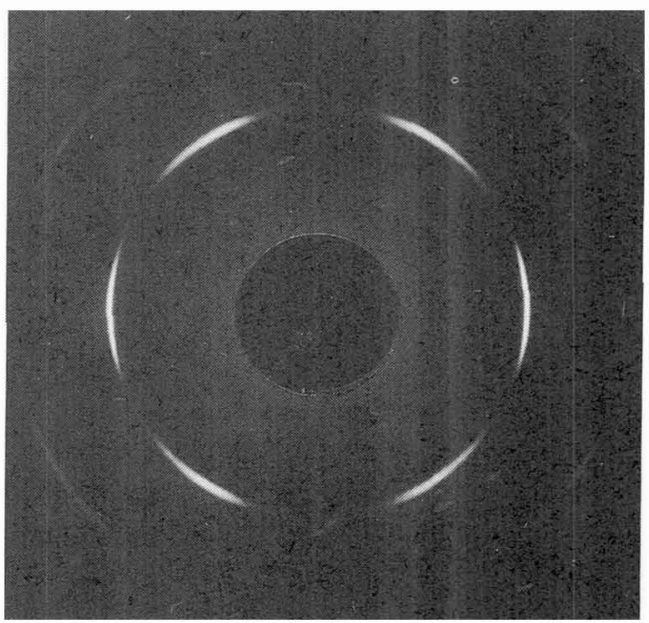

Fig. 4 - Diffraction pattern of the 32 phase at $-353 \mathrm{~K}$. After $67.2 \%$ cold deformation and annealing (823 $\mathrm{K}, 180 \mathrm{~s})$ under tensile stress.

(b)

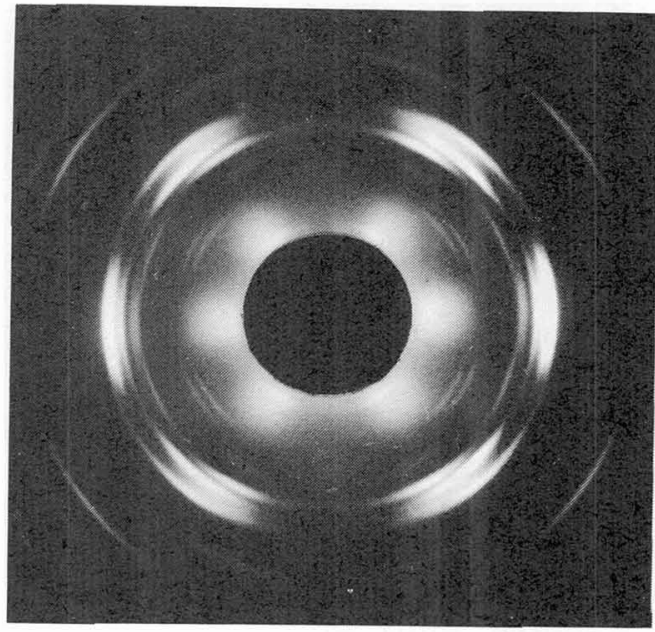

Fig.5 - Diffraction patterns of wires after cold drawing, annealing (823 $\mathrm{k}, 180 \mathrm{~s})$ under tensile stress, heating above $A_{f}$ for $2 \mathrm{~s}$, and thermomechanical cycling. (a) $20.9 \%$ cold deformation, 52604 cycles, (b) $67.2 \%$ cold deformation, 480202 cycles. 
The existence of the $<111\rangle$ fiber texture in the cubic B2 phase together with the [101], [101], [110] and [110] fiber texture components in the monoclinic B191 phase, is in agreement with the assumed orientation relationship between the two phases [7]. The same fiber texture was also found by Bührer et a1.[8] in the B2 phase of equiatomic $\mathrm{Ti}-\mathrm{Ni}$ alloy wire by means of neutron diffraction.

\section{4 - CONCLUSIONS}

-Martensitic Ti-44Ni-5Cu (at \%) wire ( $A_{f}-340 \mathrm{~K}$ ) shows after cold drawing and annealing $(823 \mathrm{~K}, 180 \mathrm{~s})$ under tensile stress, a fiber texture with the [110], [1i0], [101] and [ij01] directions parallel to the wire axis. There is a preference for the [i 101$]$ texture component.

-The preference for the [i.01] component disappears after heating the wire above $A_{f}$ and cooling down to ambient temperature.

-Subsequent thermomechanical cycling restrengthens the preference of the [ī01] component in the martensitic wire.

-In the monoclinic unit cell of the martensitic phase the length of the [101] vector is greater than those of the [110], [1i0] and [101] vectors. This means that the preference of the [ij01] fiber texture component can be explained in terms of the best accomodation of this component to tensile strain deformation during wire drawing and thermomechanical cycling.

- On heating above $A_{f}$, the wire shows a $<111>$ fiber texture. (With the assumed orientation relationship between the B2 phase and the monoclinic martensitic phase the $\langle 111\rangle$ direction of the B2 phase is parallel to the [110], [110], [101] and [101] directions of the monoclinic phase.)

\section{ACKNOWLEDGEMENT}

The authors would like to thank Memory Metal Holland, Enschede, for cold drawing of the wire.

\section{REFERENCES}

[1] Miyazaki, S., Kimura, S., Otsuka, K. and Suzuki, Y., Scripta Met.18(1984) 883.

[2] Li, D.Y., Wu, X.F. and Ko, T., Acta Met.Mat.38 (1990) 19.

[3] Eucken, S.and Hirsch, J., Mat. Sci. Forum 56-58 (1990) 487.

[4] Cullity, B.D., Elements of X-ray Diffraction, Addison Wesley, Reading, 1978.

[5] Beyer, J., Koopman, B.J., Besselink, P.A. and Willemse, P.F., Mat. Sci. Forum $56-58(1990) 773$.

[6] Otsuka, K., Sawamura, T. and Shimizu, K., Phys. Stat. Sol.(a) 5 (1971) 457.

[7] Knowles, K.M. and Simith, D.A., Acta Met. 29 (1981) 101.

[8] Bührer, W. , Gotthardt, R. and Wechsler, M.S., Proc. ICOMAT-86, Nara, Japan (1986) 697 . 